\title{
Effects of a fish oil enriched diet on aspirin intolerant asthmatic patients: a pilot study
}

\author{
CESAR PICADO, JOSE A CASTILLO, NAHYR SCHINCA, MONTSERRAT PUJADES, \\ ANTONI ORDINAS, ANTONI CORONAS, ALBERT AGUSTI-VIDAL \\ From the Servei de Pneumologia, Servei de Dietetica, and Servei de Hemoterapia, Hospital Clinic, Facultad de \\ Medicina, Barcelona, Spain
}

ABSTRACT The effect of a fish oil enriched diet containing about $3 \mathrm{~g}$ of eicosapentaenoic acid was studied in 10 patients with aspirin intolerant asthma. Subjects were studied during six weeks on a control diet followed by six weeks on the fish oil diet in a single blind study design. They were asked to record their peak expiratory flow (PEF) twice daily, bronchodilator and steroid doses, and subjective ratings of pulmonary symptoms on diary cards. There were no significant changes in symptom scores over the six weeks of either the control diet or the fish oil diet. PEF values, however, were significantly lower during the fifth and sixth week of the fish oil diet than during the control diet $(308 v 2621 / \mathrm{min}$ week 5 and $306 v 256 \mathrm{l} / \mathrm{min}$ week 6). Bronchodilator usage was also greater during the fifth and sixth week of the fish oil diet than during the control period $(12.0 v 7.4$ and $13.0 v 7.4$ puffs a day in weeks 5 and 6). This pilot study suggests that fish diets may have a deleterious effect on patients with aspirin intolerant asthma.

Several studies have shown that leukotrienes are released after anaphylactic challenges in vivo and in vitro, ${ }^{12}$ supporting the view that these substances have an important role in asthma. Lipoxygenase inhibitors therefore might reasonably be expected to have antiinflammatory and antiasthmatic effects. Since prostaglandins, leukotrienes, thromboxanes, and prostacyclines are derived from polyunsaturated fatty acids in tissues, a possible therapeutic approach might be to provide fatty acid substrates as an alternative to arachidonic acid for cyclooxygenase and lipoxygenase enzymes. ${ }^{3}$ Epidemiological and experimental studies have shown that the proportion of fatty acid in the diet can alter tissue fatty acid composition in man. ${ }^{45}$ Eicosapentaenoic acid and other fatty acids are incorporated into cell membranes when fish oil enriched diets are administered and provoke the competitive inhibition of the products derived from arachidonic acid. The metabolites formed from eicosapentaenoic acid are less active than the arachidonic acid counterparts in eliciting various biological functions, such as

Address for reprint requests: Dr Cesar Picado, Servei de Pneumologia (hospital clinic), Villaroel 170, 08036 Barcelona, Spain.

Accepted 30 June 1987 chemotaxis and aggregation of platelets and neutrophils ${ }^{67}$ Since asthma is usually associated, to a greater or lesser degree, with a sustained inflammatory reaction, fish oil diets might be a useful therapeutic approach to the treatment of asthma.

Lee et $a l,{ }^{8}$ however, in a recent study found that a fish oil diet increased the bronchoconstrictor response to antigen challenge in passively sensitised guinea pigs. The authors suggested that the increased bronchial response might be due to inhibition of the cyclooxygenase pathway and decreased production of bronchodilator prostaglandins associated with divertion of arachidonic acid metabolites into the lipoxygenase cascade. Given that asthmatic attacks in aspirin sensitive patients might also result from the redistribution of arachidonic acid metabolism via the lipoxygenase pathway, ${ }^{9}$ Lee et al suggested that fish diets might have deleterious effects on aspirin intolerant asthma. To test this hypothesis we have studied the clinical and functional response of patients with aspirin intolerant asthma to a diet enriched with eicosapentaenoic acid.

\section{Methods}

SUBJECTS

Ten aspirin intolerant asthmatic patients (seven women and three men) with a mean age of 52 (range 
Table 1 Characteristics of patients and threshold doses of aspirin that provoke a bronchial reaction

\begin{tabular}{|c|c|c|c|c|c|c|}
\hline $\begin{array}{l}\text { Case } \\
\text { No }\end{array}$ & Sex & $\begin{array}{l}\text { Age } \\
(y)\end{array}$ & $\begin{array}{l}\text { Duration of } \\
\text { asthma }(y)\end{array}$ & $\begin{array}{l}\text { Steroid } \\
\text { dependence* }\end{array}$ & $\begin{array}{l}\text { Nasal } \\
\text { polyps }\end{array}$ & $\begin{array}{l}\text { Threshold } \\
\text { dose of } \\
\text { aspirin (mg) } \dagger\end{array}$ \\
\hline $\begin{array}{r}1 \\
2 \\
3 \\
4 \\
5 \\
6 \\
7 \\
8 \\
9 \\
10\end{array}$ & $\begin{array}{l}\mathbf{F} \\
\mathbf{F} \\
\mathbf{M} \\
\mathbf{F} \\
\mathbf{F} \\
\mathbf{M} \\
\mathbf{M} \\
\mathbf{F} \\
\mathbf{F} \\
\mathbf{F}\end{array}$ & $\begin{array}{l}33 \\
51 \\
54 \\
64 \\
59 \\
43 \\
58 \\
62 \\
65 \\
31\end{array}$ & $\begin{array}{r}7 \\
4 \\
9 \\
56 \\
10 \\
36 \\
51 \\
13 \\
54 \\
7\end{array}$ & $\begin{array}{l}+ \\
+ \\
+ \\
+ \\
+ \\
+ \\
+ \\
+ \\
- \\
-\end{array}$ & $\begin{array}{l}- \\
+ \\
+ \\
- \\
- \\
+ \\
+ \\
+ \\
- \\
-\end{array}$ & $\begin{array}{r}40 \\
300 \\
30 \\
300 \\
30 \\
150 \\
150 \\
100 \\
150 \\
500\end{array}$ \\
\hline
\end{tabular}

*Steroid dependent patients were having continuous oral and inhaled beclomethasone treatment.

$\dagger$ The dose of aspirin that caused a $30 \%$ or greater fall in FEV according to the method of Mathinson and Stevenson. ${ }^{10}$

$31-65)$ years were included in the study. Aspirin sensitivity was assessed by specific oral challenges according to the method developed by Mathinson and Stevenson. ${ }^{10}$ Patients' characteristics are shown in table 1 . Seven patients required continuous treatment with steroid tablets. These patients were asked to use a fixed dose of oral steroids and inhaled beclomethasone unless substantial clinical or functional deterioration occurred, in which case $30 \mathrm{mg}$ a day of oral prednisone for five days was recommended. Patients were also treated with a fixed dose of salbutamol (two puffs six hourly), but supplemental puffs were allowed according to symptoms. Voluntary consent was obtained from all patients and the study was carried out with the approval of the research committee.

\section{CONTROL DIET}

All subjects were given 12 capsules containing a placebo (lactose) and an eucaloric diet consisting of carbohydrate, $51 \%$; protein, $17 \%$; fat, $32 \%$; cholesterol, $200 \mathrm{mg}$; crude fibre $12.5 \mathrm{~g}$; and a polyunsaturated:saturated fatty acid ratio of 0.9 .

\section{EXPERIMENTAL DIET}

The experimental diet was also eucaloric. It had a composition similar to that of the control diet except that it was enriched with about $3 \mathrm{~g} /$ day of omega-3 $\left(\omega_{3}\right)$ fatty acids given in the form of $150 \mathrm{~g}$ of sardine meal and supplemented by 12 capsules of commercially available fish oil (MaxEPA). A sample of the MaxEPA was analysed by gas chromatography for fatty acid composition (table 2).

Table 2 Fatty acid composition of a capsule of MaxEPA

\begin{tabular}{lclc}
\hline Acid & $\%$ & Acid & $\%$ \\
\hline Miristic & 8 & Linoleic & 1 \\
Palmitic & 18 & Linolenic & 0.6 \\
Palmitoleic & 9 & Arachidic & $2 \cdot 6$ \\
Heptocanoic & $1 \cdot 7$ & Arachidonic & 0.8 \\
Estearic & $3 \cdot 6$ & Eicosapentaenoic & 18.4 \\
Oleic & 18 & Docosahexaenoic & 10.5 \\
\hline
\end{tabular}

\section{STUDY DESIGN}

After a pretrial assessment period of two weeks to ensure the correct use of the peak flow meter, patients were put on the control diet for six weeks. Then the fish oil diet was given for a further six weeks. Patients were told that both diets were experimental. They were seen every two weeks at the outpatient clinic and requested to measure peak expiratory flow (PEF), using a MiniWright peak flow meter, in the morning and at night before taking the bronchodilator aerosol and to record the values on diary cards. They were also asked to record bronchodilator usage and steroid doses and to rate their pulmonary symptoms (cough and dyspnoea) on a scale of $0-10$, lower ratings indicating increasing severity of symptoms. The six week period was chosen on the basis of a previous study, ${ }^{7}$ in which the effect of a similar diet on neutrophil function was evident after five weeks of treatment.

\section{MEASUREMENT OF SERUM FATTY ACIDS AND} THROMBOXANE $B_{2}$ CONCENTRATIONS

Blood samples were drawn by venepuncture at the beginning and at the end of the six weeks of the control and experimental diets. Platelet thromboxane $A_{2}$ production was evaluated, by measuring the concentration of its stable metabolite, thromboxane $B_{2}$, in appropriately diluted serum by means of radioimmunoassay." The cross reactivity between thromboxane $B_{2}$ and $B_{3}$ with this assay is unknown. Serum fatty composition was determined by gas-liquid chromatography.

\section{STATISTICAL ANALYSIS}

Values are expressed as means with standard deviations or standard errors in parentheses, and compared by means of two way analysis of variance, Scheffè's contrasts, Student's paired $t$ test, Wilcoxon's signed rank test and the $\chi^{2}$ test. 


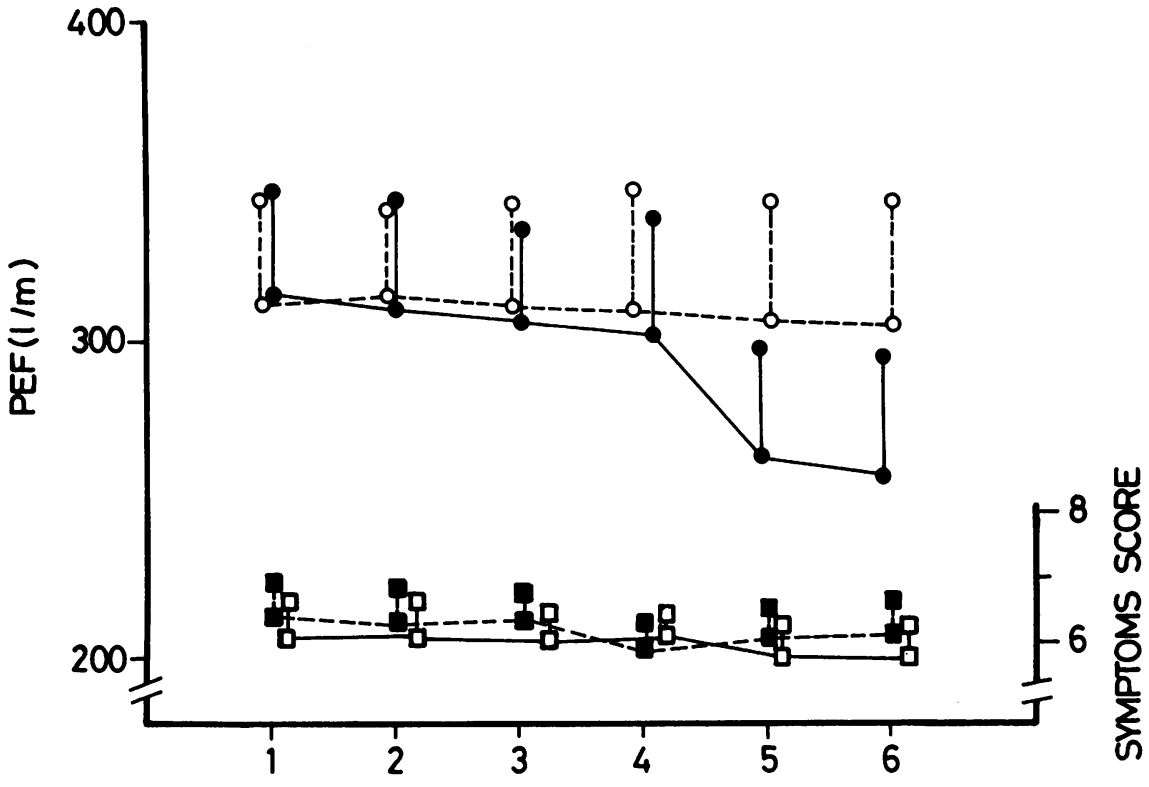

Fig 1 (Upper) Means and standard errors of the sum of morning and evening weekly peak expiratory flow (PEF) values for the 10 patients during each six week period. O---O---O control diet; - fish oil enriched diet. Significant reductions in mean PEF were noted during the fifth and sixth week of the fish oil diet. (Lower) Means and standard errors of weekly assessment of clinical symptoms in ten patients during the control and experimental diets. $\square$-.- control diet, $\square-\square$ fish oil diet. Symptom score indicates increasing severity of symptoms. No significant differences were observed.

TIME (weeks)

\section{Results}

\section{CLINICAL SYMPTOMS}

There was no change in symptom score with either the control or the fish oil diet (two way ANOVA test) (fig $1)$.

\section{PEAK EXPIRATORY FLOW}

There was no significant change in PEF during the period on the control diet (two way ANOVA). A significant reduction in mean PEF was, however, observed during the fifth and sixth weeks of the fish oil diet $(p<0.05)$ (two way ANOVA and Scheffè's contrasts). The difference between control PEF values and PEF during the fish oil diet's fifth (308 (SEM 111) vs $262(104) \mathrm{l} / \mathrm{m}$ ) and sixth week (306 (126) v 256(115)) were also significant (Student's paired $t$ test, $\mathrm{p}<0.05)$.

\section{BRONCHODILATOR AND STEROID TREATMENT}

There were no significant differences in steroid use during the control and experimental diet periods; nor was there any significant difference in the number of puffs of bronchodilator (salbutamol) taken during the first four weeks of the two diets (table 3 ). There was, however, a modest but significant increase in the use of bronchodilator during the fifth and sixth weeks of the fish oil diet ( $p<0.05)$ (two way ANOVA) (table 3). A significant difference was also found between the control and the fish oil diet period in the use of bronchodilator inhaler during the fifth and sixth weeks (Student's paired $t$ test, $\mathrm{p}<0.05$; table 3).

SERUM THROMBOXANE $B_{2}$ CONCENTRATIONS

The mean basal value for thromboxane $B_{2}$ before the control diet was 295 (SEM 105) ng/ml and the mean value before the experimental diet was 320 (147) $\mathrm{ng} / \mathrm{ml}$. The concentrations of thromboxane $\mathbf{B}_{2}$ decreased significantly after six weeks of the fish oil enriched diet $(146(103) \mathrm{ng} / \mathrm{ml})$ (Student's $t$ test, $\mathrm{p}<0.001$; fig 2 ).

\section{SERUM FATTY ACID COMPOSITION}

There were significant increases in eicosapentaenoic acid and docosahexaenoic acids after the fish oil diet with respect to basal values $\left(\chi^{2}\right.$ test, $p<0.01$; table 4$)$.

Table 3 Bronchodilator and oral steroid treatment during control diet and fish oil enriched diet (FOED) (means with standard deviations in parentheses)

\begin{tabular}{|c|c|c|c|c|}
\hline \multirow{2}{*}{$\begin{array}{l}\text { Week } \\
\text { No }\end{array}$} & \multicolumn{2}{|c|}{$\begin{array}{l}\text { Bronchodilator } \\
\text { (puffs/day) }\end{array}$} & \multicolumn{2}{|l|}{$\begin{array}{l}\text { Oral steroids } \\
\text { (mg/day) }\end{array}$} \\
\hline & Control diet & FOED & Control diet & FOED \\
\hline $\begin{array}{l}1 \\
2 \\
3 \\
4 \\
5 \\
6\end{array}$ & $\begin{array}{l}8 \cdot 1(9 \cdot 1) \\
6 \cdot 3(6 \cdot 2) \\
6 \cdot 1(6 \cdot 7) \\
7 \cdot 0(8 \cdot 4) \\
7 \cdot 4(6 \cdot 9) \\
7 \cdot 4(7 \cdot 5)\end{array}$ & $\begin{array}{c}8 \cdot 2(8 \cdot 2) \\
7 \cdot 5(7 \cdot 5) \\
7 \cdot 5(6 \cdot 7) \\
6 \cdot 3(5 \cdot 3) \\
* 12.0(9 \cdot 5) \\
* 13.0(11 \cdot 0)\end{array}$ & $\begin{array}{r}9.6(2.3) \\
8 \cdot 8(2 \cdot 1) \\
9.6(2 \cdot 3) \\
10.0(3.2) \\
9 \cdot 2(3.4) \\
10.2(2.6)\end{array}$ & $\begin{array}{r}9.0(2.1) \\
9.4(2.7) \\
10.1(3.1) \\
9.6(2.8) \\
8.9(2.1) \\
11.9(3.9)\end{array}$ \\
\hline
\end{tabular}




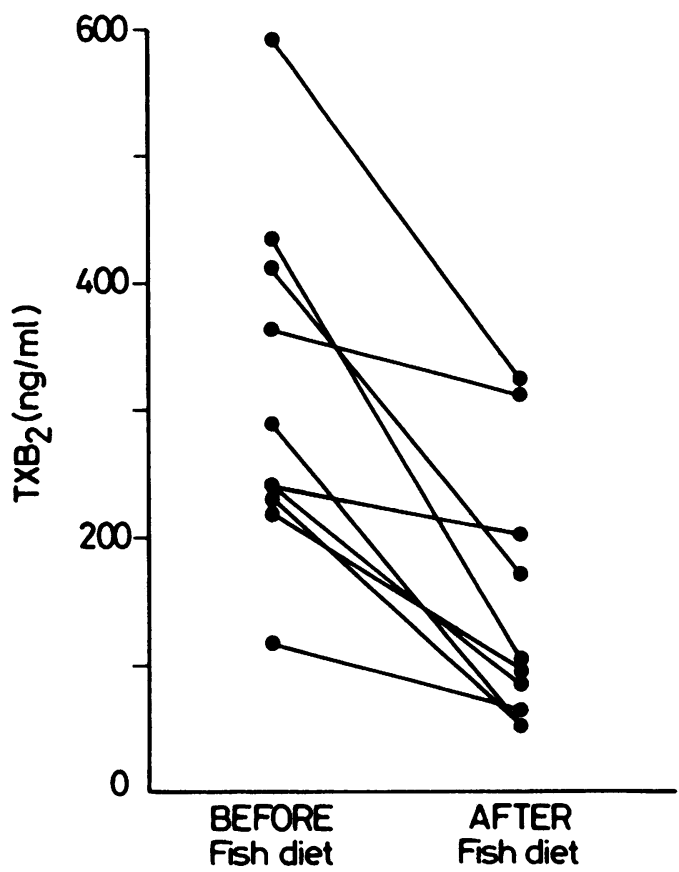

Fig 2 Individual serum thromboxane $B_{2}\left(T X B_{2}\right)$ concentrations before and after the fish oil enriched diet.

\section{Discussion}

Eicosapentaenoic acid is prominent in fish oil and is incorporated into the tissue phospholipids of humans and animals consuming fish diets. The leukotriene (LT) $B_{5}$ and thromboxane $A_{3}$ derived from eicosapentaenoic acid are less active than their counterparts derived from arachidonic acid in eliciting neutrophil chemotaxis and aggregation. ${ }^{612}$ This is not, however, the case for $\mathrm{LTC}_{5}$, which is as potent a bronchoconstrictor agent as $\mathrm{LTC}_{4}{ }^{13}$

Dietary enrichment with a daily dose of $3.2 \mathrm{~g}$ of eicosapentaenoic acid for six weeks in normal subjects produced a substantial increase in the eicosapentaenoic acid content of neutrophils and monocytes. The incorporation of eicosapentaenoic acid into these

Table 4 Fatty acid composition (mean (SD)\%) of total serum fatty acid) before and after control diet and fish oil enriched diet (FOED)

\begin{tabular}{llll}
\hline & $\begin{array}{l}\text { Before } \\
\text { control diet }\end{array}$ & $\begin{array}{l}\text { Before } \\
\text { FOED }\end{array}$ & $\begin{array}{l}\text { After } \\
\text { FOED }\end{array}$ \\
\hline AA (20:4) & $6.18(1.32)$ & $6.40(1.93)$ & $\begin{array}{l}5.98(1.24) \\
\text { EPA (20:5) }\end{array}$ \\
$\begin{array}{lll}0.61(0.43) \\
\text { DCHA (22:6) } 1.12(1.62)\end{array}$ & $\begin{array}{l}0.63(0.57)^{*} \\
1.23(1.72)^{*}\end{array}$ & $\begin{array}{l}* 4.14(1.45) \\
4.29(1.36)\end{array}$ \\
\hline
\end{tabular}

${ }^{*} \mathrm{p}<0.01$ ( $\chi^{2}$ test $)$.

AA-arachidonic acid; EPA —eicosapentaenoic acid;

DCHA-docosahexaenoic acid. cells was accompanied by a reduction in the release of $\mathrm{LTB}_{4}$ and inhibition of chemotactic and adherence neutrophilic functions. ${ }^{7}$ Thus eicosapentaenoic acid might modulate the inflammatory reaction and thereby aid in the management of inflammatory diseases such as chronic bronchial asthma. Lee et al, ${ }^{8}$ however, in a recent study of anaphylaxis in guinea pigs, found that a fish oil diet facilitated the nonhistamine mediated bronchoconstrictor response. When animals given a fish oil diet were pretreated with a dose known to inhibit the cyclo-oxygenase pathway, there were no significant modifications in the anaphylactic response. This suggests that the fish oil diet could increase the immunologically mediated pulmonary response through the inhibition of the cyclooxygenase pathway, which is a mechanism similar to that by which aspirin is thought to provoke attacks of asthma in some patients. Lee et al reasoned that, if this were true, aspirin intolerant subjects might experience an exacerbation of symptoms if they had a diet enriched with eicosapentaenoic acid.

In this study the fish oil diet clearly modified the serum concentrations of fatty acids and immunoreactive thromboxane $\mathbf{B}_{2}$. Although the production of metabolites derived from eicosapentaenoic acid was not measured, we may assume that the diminished synthesis of thromboxane $B_{2}$ was a consequence of the experimental diet. Modification of platelet thromboxane $B_{2}$ production could be due to a compensated increase in thromboxane $B_{3}$ or to an effective inhibition of the cyclooxygenase pathway. Since the dose of eicosapentaenoic acid given to our patients was similar to that administered by Lee et $a l^{7}$, we may reasonably assume that in this study the fish oil diet caused substantial modifications in $\mathrm{LTB}_{4}$ and $\mathrm{LTB}_{5}$ concentrations, as well as in other cyclooxygenase and lipoxygenase derived metabolites.

A significant decrease in PEF and a small increase in the dose of $\beta$ adrenergic bronchodilator were observed while the patients were having the experimental diet. There was, however, no significant change in the patients' subjective assessment of symptoms. Dissociation between clinical evaluation and PEF measurements in our patients might be due to relatively small reduction in PEF and the poor correlation that frequently exists between symptoms and functional changes in bronchial asthma. ${ }^{14}$ The increased bronchial obstruction observed in the fifth week is consistent with the results of previous studies, where the modification of lipoxygenase products derived from arachidonic acid was seen after at least three weeks of a fish oil enriched diet. ${ }^{7}$

The single blind design used in this study was preferred to a crossover design because the washout period for a fish oil diet is unknown. Ideally, definitive studies must be of a double blind and crossover design, 
but these have limitations when the washout period for preventing any carryover effect of a treatment is not firmly established. ${ }^{15}$ Although the effects of fish oil diets on bronchial asthma require more studies our results support the suggestion of Lee et $a l^{8}$ that an alteration in the balance between the metabolites derived from the cyclooxygenase and lipoxygenase pathways by fish oil supplements may have unfavourable effects on aspirin intolerant asthmatic patients. Consumption of the fish oil diet for a longer time presumably would have led to an additional increase in bronchial obstruction and detectable clinical deterioration.

Different results might be obtained in aspirin tolerant asthmatic patients or even in those patients in whom non-steroidal anti-inflammatory drugs cause bronchodilatation. $^{16}$

This work was supported in part by a grant from Sociedad Española Patologia Respiratoria.

\section{References}

1 MacGlashan DW, Schleimer RP, Peter SP, et al. Generation of leukotrienes by purified human lung mast cell. $J$ Clin Invest 1982;70:747-51.

2 Stechshutte DJ, Orange RP, Austen KF. Detection of slow reacting substances of anaphylaxis (SRS-A) in plasma of guinea pigs during anaphylaxis. J Immunol 1973;111:1585-9.

3 Lee TH, Arm JP. Prospects for modifying the allergic response by fish oil diets. Clin Allergy 1986;16:89-100.

4 Goodnight SH, Harris WS, Connor WE. The effects of dietary 3 fatty acids on platelet composition and function in man: a prospective, controlled study. Blood 1981;58:880-5.
5 Thorngren M, Gustafson A. Effects of 11-week increase in dietary eicosapentaenoic acid on bleeding time, lipids and platelet aggregation. Lancet 1981;ii:1190-3.

6 Terano T, Salmon JA, Moncada S. Biosynthesis and biological activity of leukotriene B5. Prostaglandins 1984;27:217-32.

7 Lee TH, Hower RL, Williams JD, et al. Effect of dietary enrichment with eicosapentaenoic acid and docosahexaenoic acids on in vitro neutrophil function. $N$ Engl $J$ Med 1985;312:1217-23.

8 Lee TH, Austen KF, Leitch AG, et al. The effects of a fish oil enriched diet on pulmonary mechanics during anaphylaxis. Am Rev Respir Dis 1985;132:1204-9.

9 Slepian IK, Mathews HP, McLean JA. Aspirin-sensitive asthma. Chest 1985;87:386-91.

10 Mathinson DA, Stevenson DD. Hypersensitivity to nonsteroidal antiinflammatory drugs: indications and methods. J Allergy Clin Immunol 1979;64:669-74.

11 Weksler BB, Pett SB, Alonso D, et al. Differential inhibition by aspirin of vascular and platelet prostaglandin synthesis in atherosclerotic patients. $N$ Engl J Med 1983;308:800-5.

12 Prescott SM, Zimmerman GA, Morrison S. The effects of a diet rich in fish oil on human neutrophils: identification of leukotriene B5 as a metabolite. Prostaglandins 1985;30:210-27.

13 Ford-Hutchinson AW, Bray MA, Doig MV, Shipley ME, Smith MJH. Leukotriene B a potent chemokinetic and aggregating substance from polymorphonuclear leukocytes. Nature 1980;286:264-5.

14 Burdon JGW, Juniper EF, Killian FE, Hargreave FE, Campbell EJM. The perception of breathlessness in asthma. Am Rev Respir Dis 1982;126:825-8.

15 Nicklas RA, Sheffer AL, Adkinson NF, et al. Workshop 3: Study design. J Allergy Clin Immunol 1986;78(part 2):507-17.

16 Kordansky D, Adkinson NJ, Norman PS, Rosenthal RR. Asthma improved by nonsteroidal antiinflammatory drugs. Ann Intern Med 1978;88:508-11. 